This article has been scanned by iThenticat No plagiarism detected

Volume 3, Issue 6, December 2021

p. $30-40$

\title{
A PROPOSED TRAINING PROGRAM TO DEVELOP SELF-DEVELOPMENT FOR ARAB SCHOOL PRINCIPALS WITHIN THE GREEN LINE
}

http://dx.doi.org/10.47832/2757-5403.6-3.3

\section{Sawsan KARA ${ }^{1}$ \& Mawaheb MOSTAFA ${ }^{2}$}

\begin{abstract}
:
The study aimed to propose training program to develop selfdevelopment for Arab school principals within The Green Line. To achieve the purpose of the study, a qualitative design based on content analysis was used. The results of the study indicated that the proposed training program focuses on self-development for Arab school principals by focusing on the aspects and skills related to self-development, which would positively enhance principals' ability to interact positively with different situations; providing them with experience and knowledge about professional aspects; enhancing their sensitivity to problems; developing decision-making skills, increasing their flexibility in dealing with situations, circumstances and crises.
\end{abstract}

Key words: Proposed Training Program, Self-Development, Arab

Received: 22/09/2021

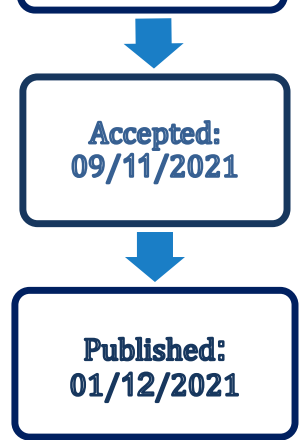
School Principals, The Green Line.

\footnotetext{
${ }^{1}$ Prof. Dr. , Paris College of International Education (PCIE), y.kara@bezeqint.net, https://orcid.org/0000-00034575-6146

${ }^{2}$ Dr. , The Ministry of Education, mawaheb.mostafa@isma.org.il, https://orcid.org/0000-0002-1902-1173
}

Copyright $(\mathcal{C}$ Published by IJHER Journal, www.ijherjournal.com Rimar Academy, Fatih, Istanbul, 34093 Turkey

All rights reserved 


\title{
برنامج تدريبي مقترح لتظوير الذات لاى مديري المدارس العربية داخل الخط الأخضر
}

\section{سوسن يوسف قرا 3 \\ مواهب مصطفى}

\begin{abstract}
الملخص
هدفت الدراسة إلى اقتر اح برنامج تدريبي لنطوير الذات لدى مديري المدارس العربية داخل

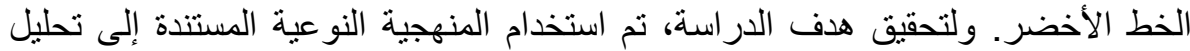

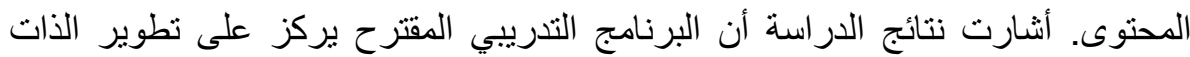

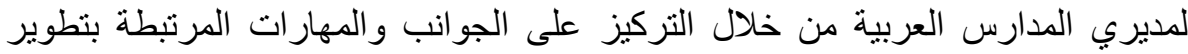

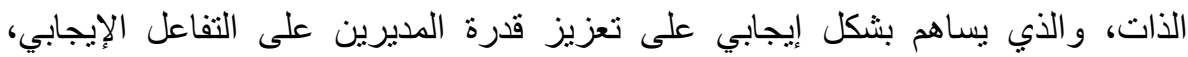

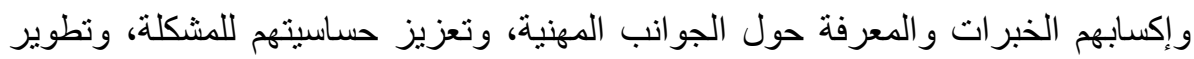

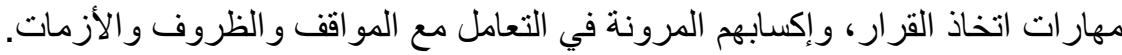

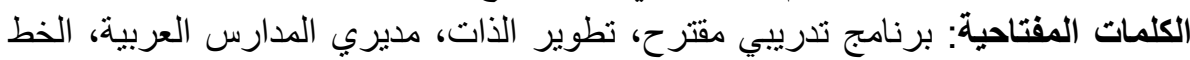

يعد تطوير الذات من المهارات الأساسية في الحالية الأكاديمية و الوظيفية للعاملين في مختلف القطاعات، إذ إن العمل على الكائ

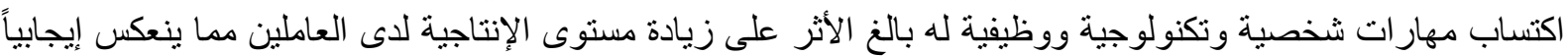

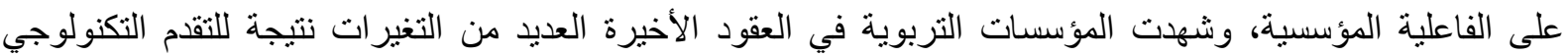

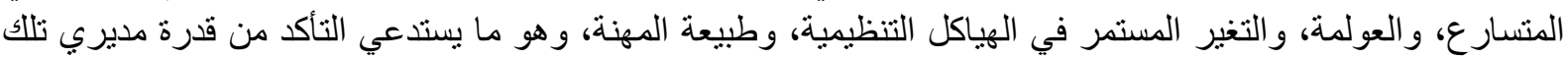
المؤسسات على قيادة وتوجيه الجهود نحو تحقيق التميز، و البحث عن وسائل بديلة لتطوير المعرفة و المهار ات لكئ لكي تكون

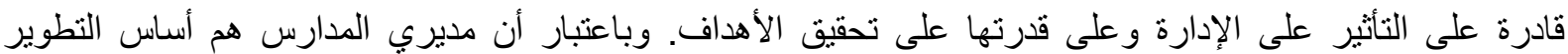

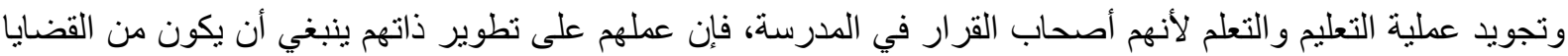

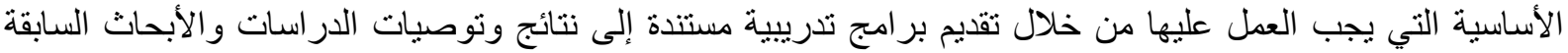

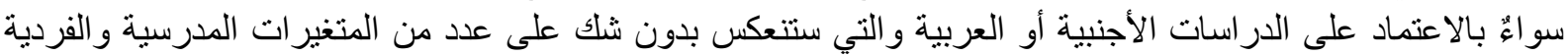

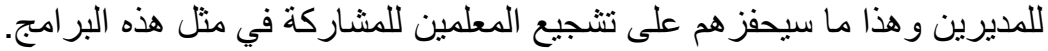

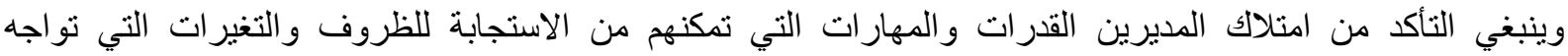

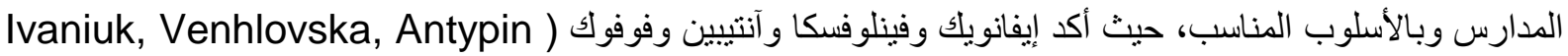
\& \&ovchok, 2020

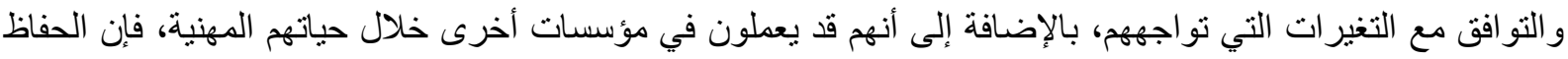
على كفاءتهم المهنية يصبح مسؤولية شخصية.

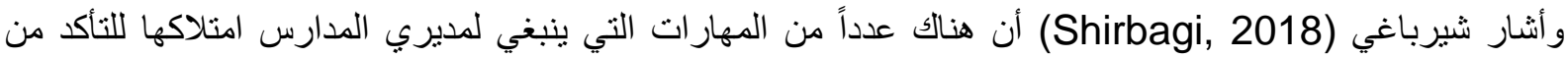

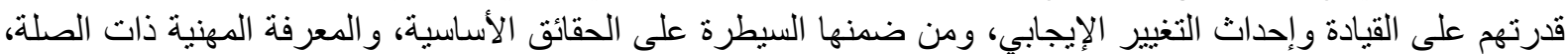

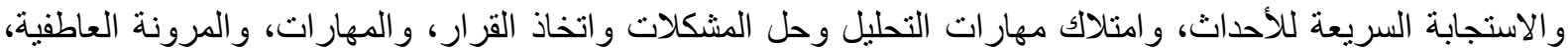

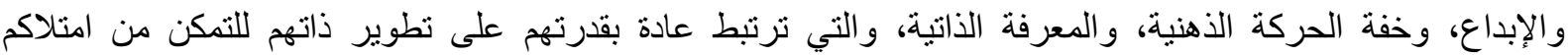

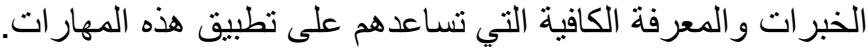

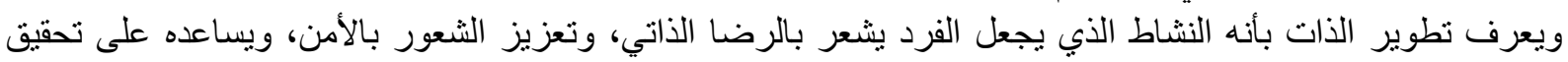

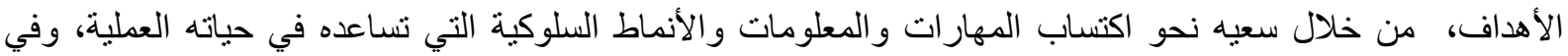

تطوير مهار اته وخبر اته (Zawadzka \& Szabowska-Walaszczyk, 2014). 
ويعرف تطوير الذات بأنه: الأنشطة المقصودة لاكتساب الخبرات والمعارف الجديدة، والتي نؤثر على قدرتهم على إحداث التغيير من خلال دور هم القيادي، والقدرة على إدارة التغيرات والظروف التئية ينتم مواجنها في سبيل تحقيق أهداف المؤسسة التعليمية (Stancui, 2019). و أنشار هاريس وأورث (Harris \& Orth, 2019) إلى أن نطوير الذات هو سعي الأفراد نحو تطوير المهارات

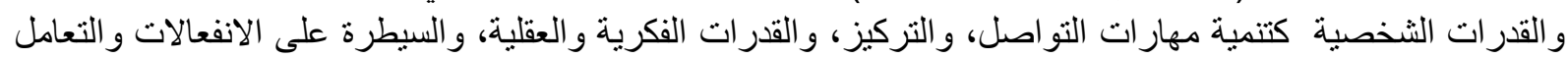

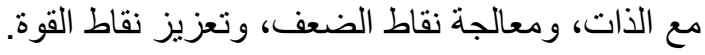

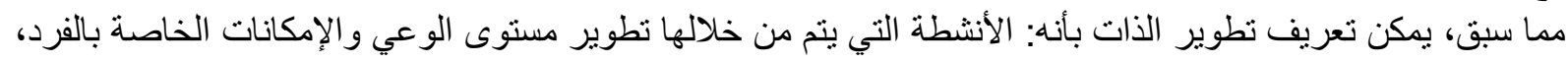

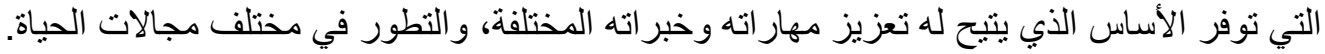

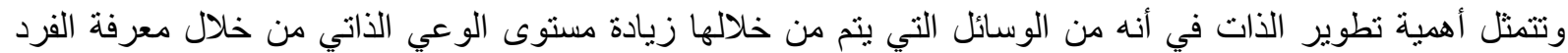

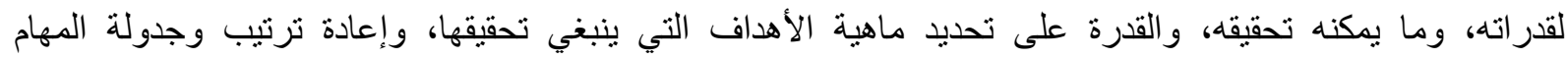

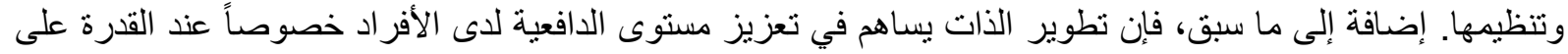

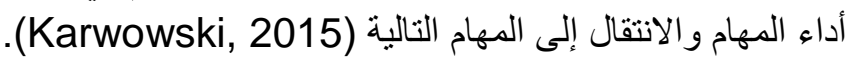
ويتيح تطوير الذات من قدرة الفرد على الحصول على فرص جديدة نتيجة لما يمتلكه من خبرات واتلفه ومهار ات لأنه مهيأ لها،

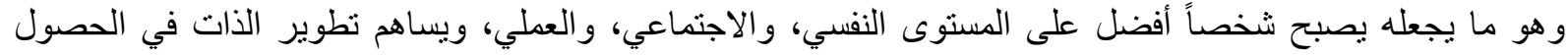

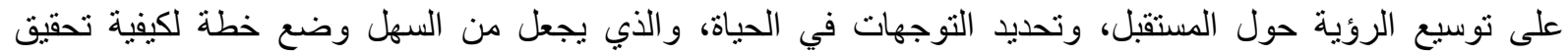

الأهداف (Spry \& Marchant, 2014).

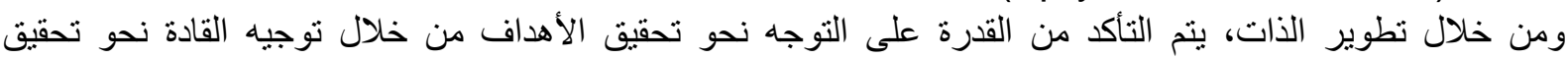

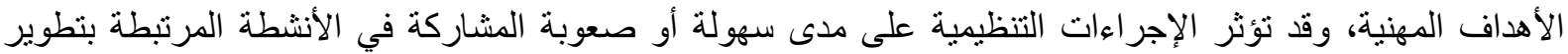
الذات (Osborne \& Hammoud, 2017)، وينم التركيز على عدد من الجو انب لنطوير الذات، وهي:

ـ الجاتب الروحي: ويرتبط بالدين و العبادة و الجوانب الروحية، ويساهم تطويره في بناء اتصـال أعمق مع العالم، حيث إنها

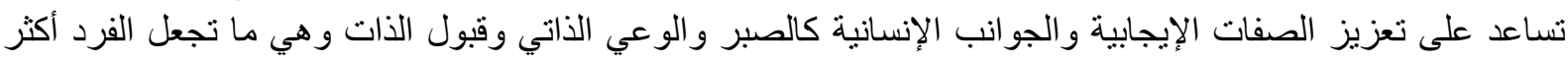

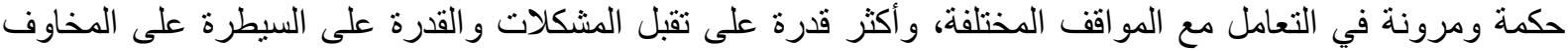

.(Villani, D., Sorgente, A. \& lannello, 2019)

ـ الجانب العاطفي: يساهم الجانب العاطفي في تتمية العلاقات الثخصية والمهنية من خلال اكتساب المهار ات الاجتماعية

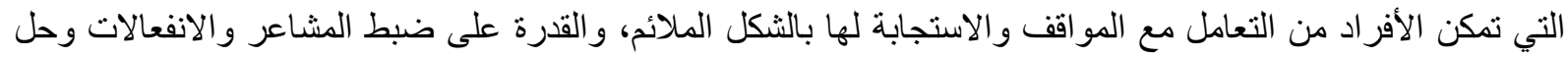
المشاكل بهدوء، وهو ما يعزز مستوى الثقة والقبول المجتمعي لهم ( Worthington, Hook, Davis \&

(McDaniel, 2011

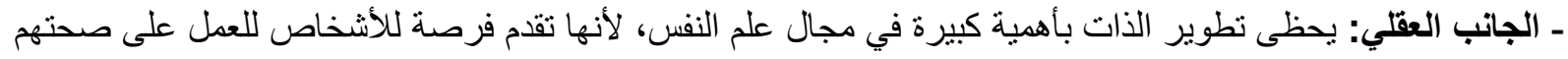

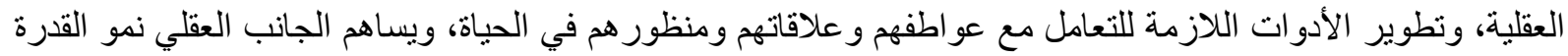

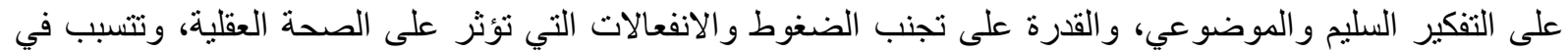

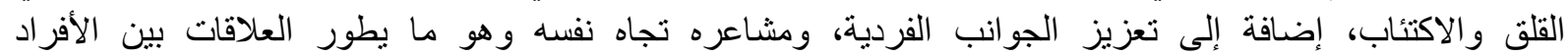

.(Hayward \& Krause, 2014)

ـ الجاتب الاجتماعي: وتتعلق بتتمية أساليب التواصل وبناء العلاقات الإيجابية بين الأفراد لتحقيق التفاعل بين الآخرين

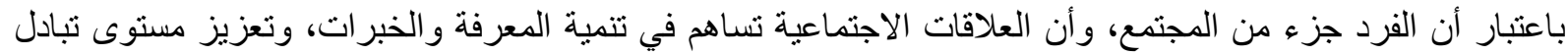

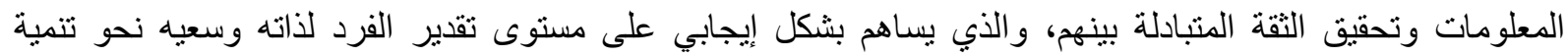

مهار اته المختلفة (Harris \& Orth, 2019).

ـ الجاتب الصحي: تعدّ الصحة من الجوانب المهمة التي ينبغي للأفراد التركيز على الحفاظ عليها وتحسينها وتتضنمن

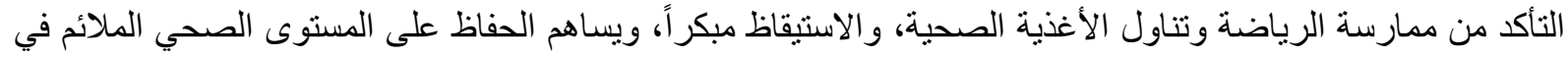
قدرة الأفر اد على أداء المهام والأنشطة اليومية والأنشطة المرتبطة بمكان العمل (VanderWeele, 2017).

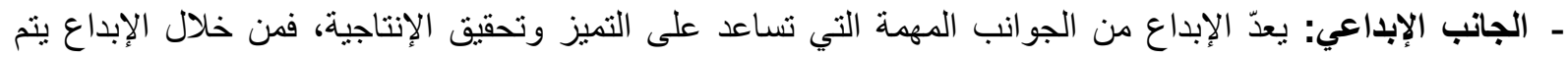

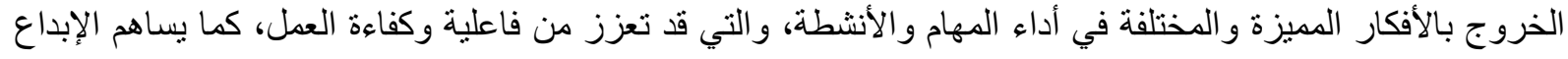




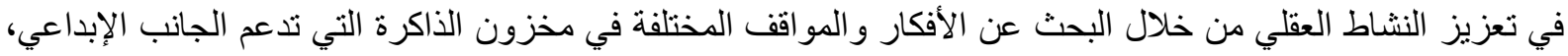
و الذي يجعل الفرد أكثر قدرة على الثعور بالإنجاز و السعادة، وبتقدير الذات النات (Karwowski, 2015).

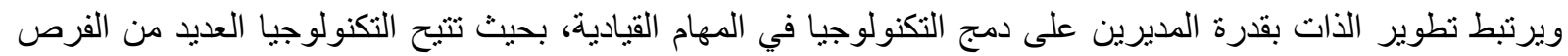

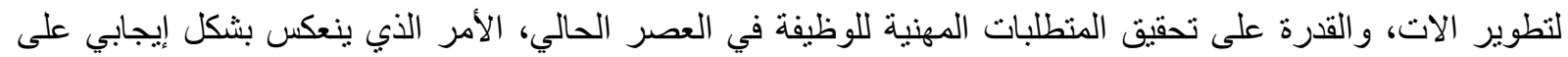

أداء المهام وتنظيمها، وتأطير المهارات التعليمية الضرورية لتهية لتطوير الذات (Nasreen \& Odhiambo, 2018)

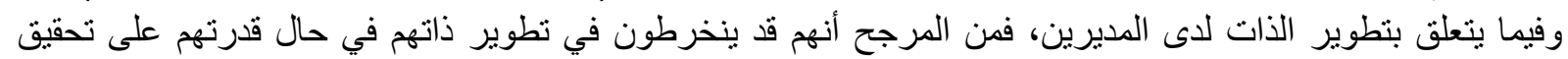

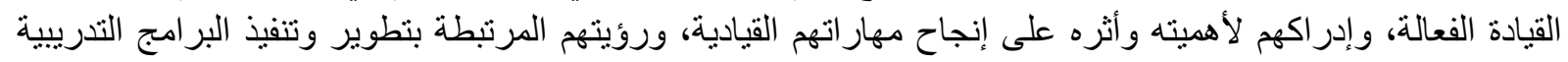

المساهمة بالتنمية الذاتية (Shirbagi, 2018).

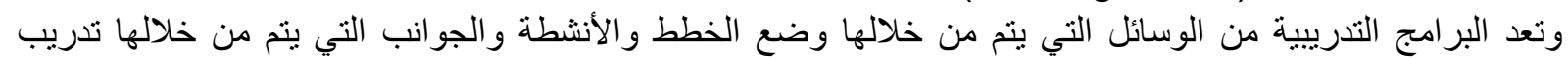

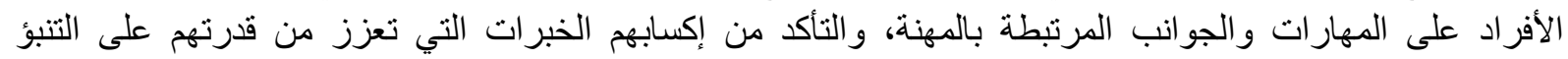

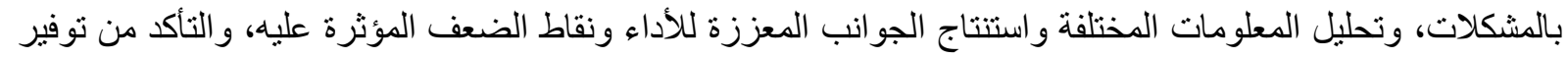

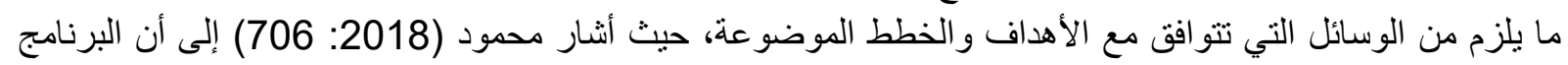

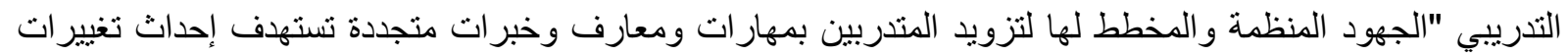

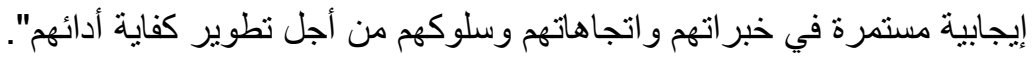

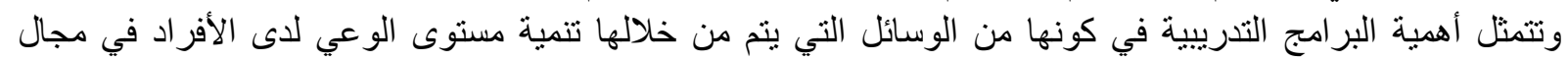

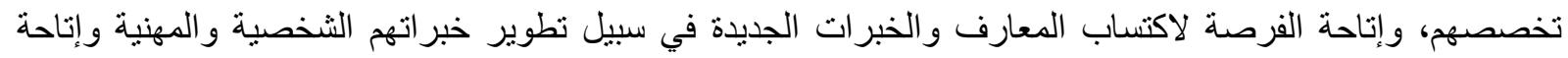

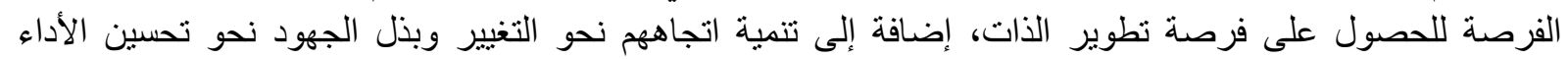

.(Megheirkouni, (2016)

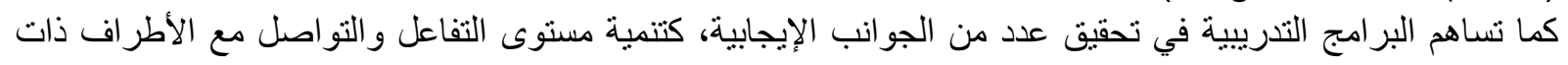

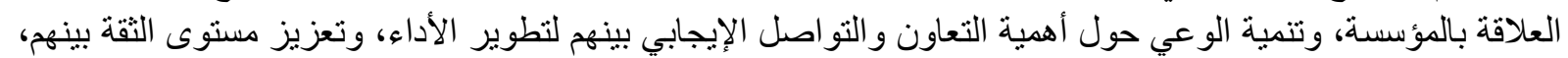

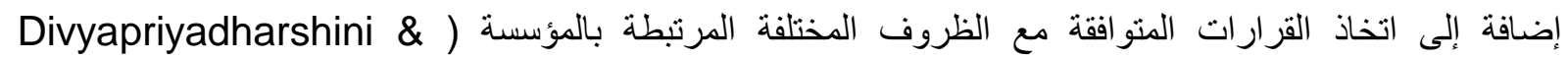

.(Devika, 2020

و هناك عدد من الدراسات التي أنتارت إلى البرامج التدريبية وتطوير الذات لدى المديرين؛ حيث أجرى العبد الكريم و الملا

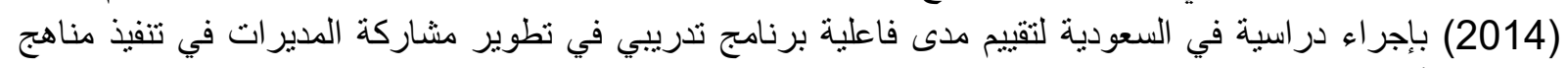

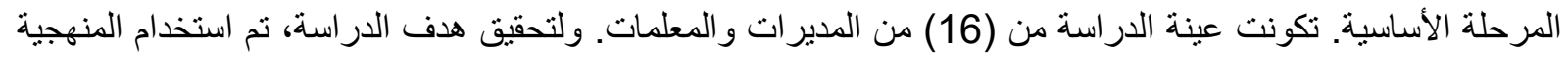

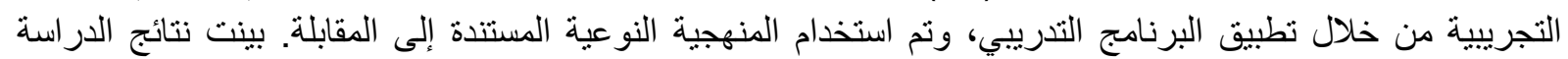

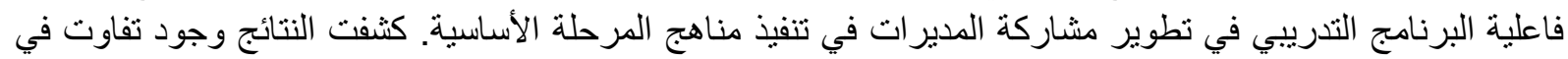

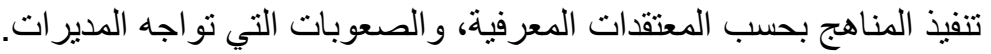

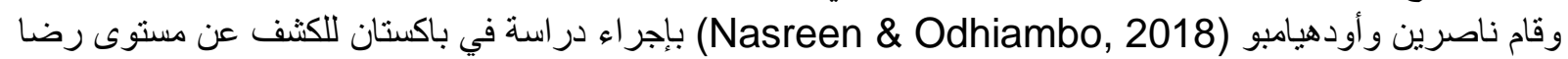

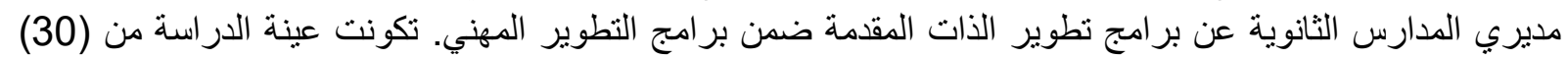

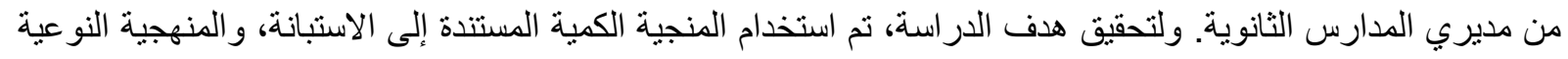

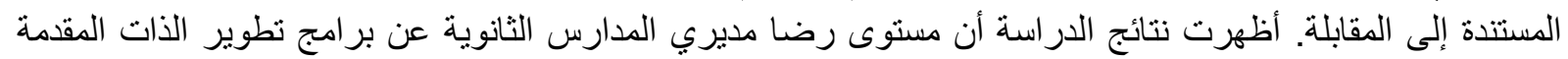

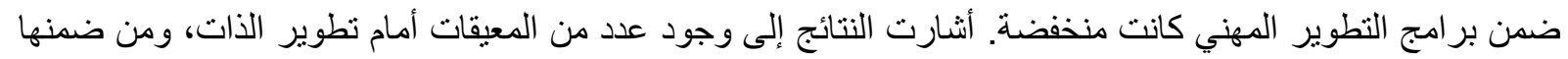

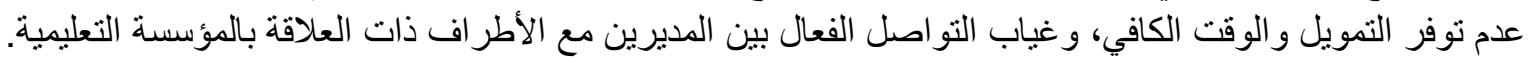

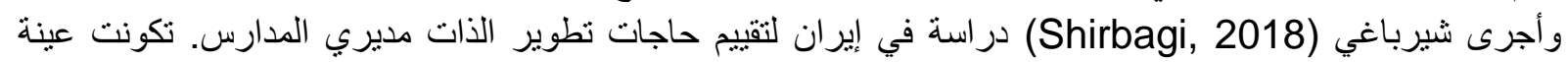
الدراسة من (150) من مديري المدارس. ولتحقيق هدف الدراسة، تم استخدام المنهجية الكمية المستندة إلى الاستبانة.

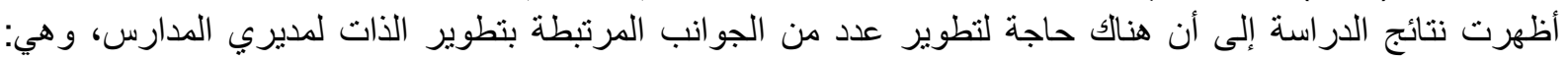

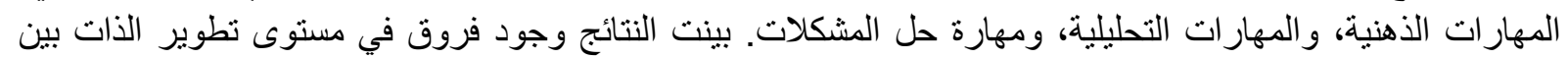

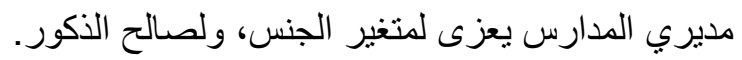

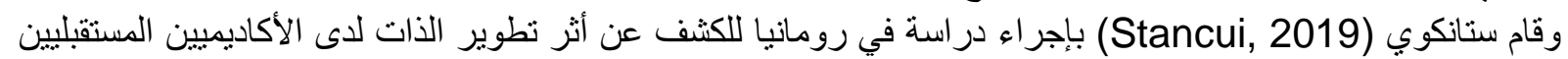

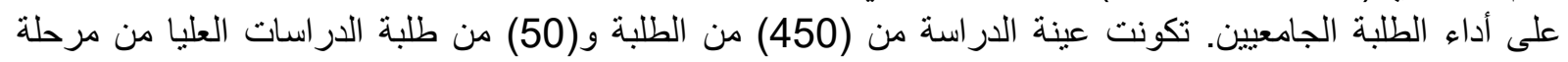

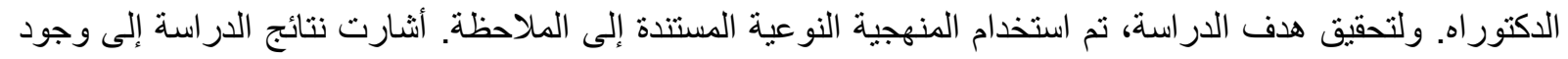
أثر إيجابي لنطوير الذات لدى الأكاديميين المستقبليين على أداء الطلبة الجامعيين. 
وسعت دراسة سنكار وأونين وعرار (Sincar, Önen \& Arar, 2020) التي أجريت في نركيا إلى الكثف عن

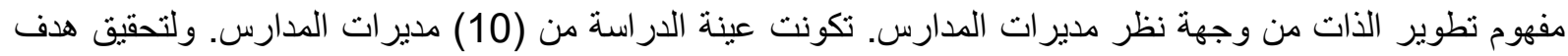

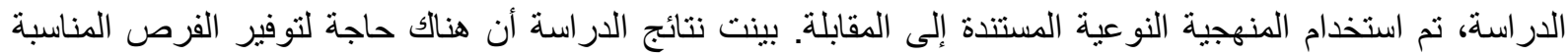
للمدير ات لتطوير ذاتهن، خصوصاً في ظل الالتزامات التي يتحملنها في العمل وفي المنزل، وهو ما يقلل من قدرتهنّ على التى الته

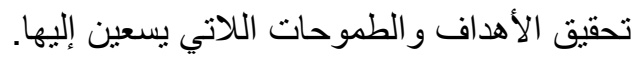

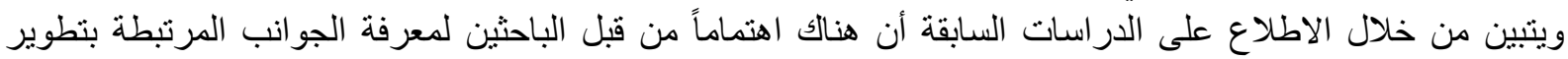

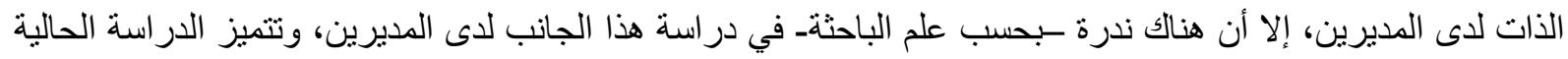

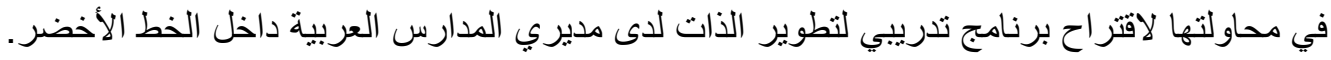

\section{مشكلة الاراسة وأسئلتها}

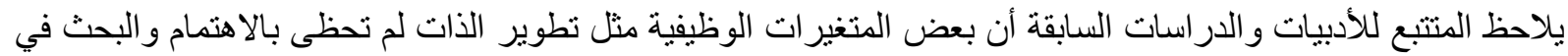

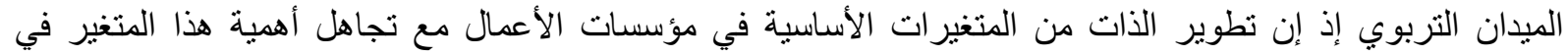

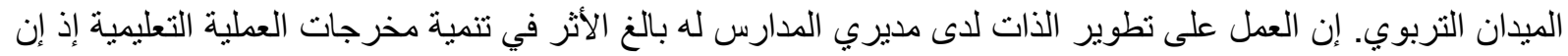

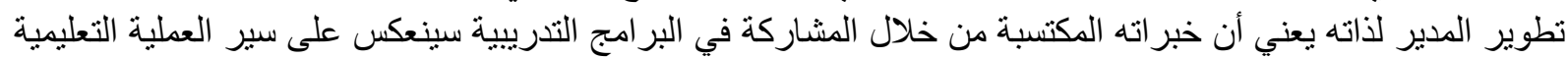

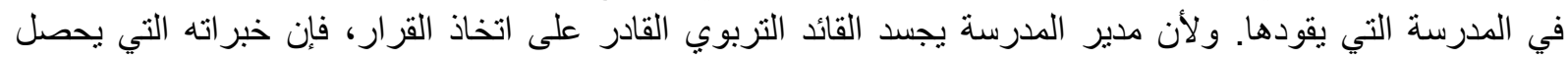

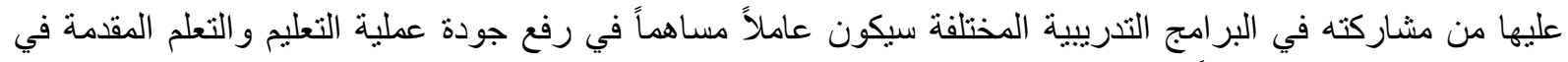

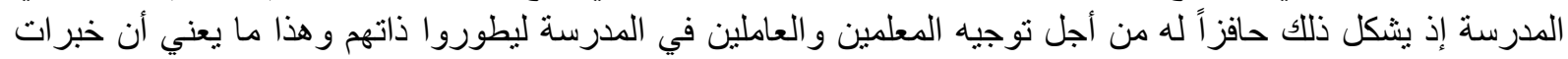
التعلم المقدمة في المدرسة ستكون أفضل.

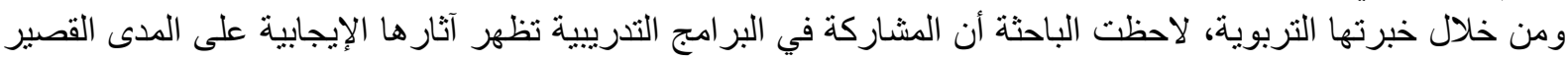

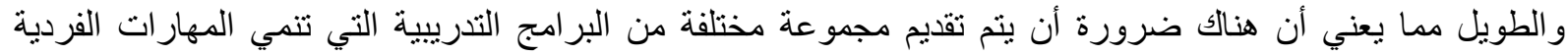

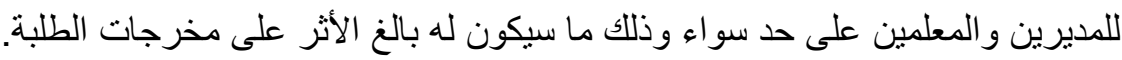

أسئلة الاراسة تحاول الدراسة الإجابة عن السؤال الرئيسي الآتي: "ما البرنامج التدريبي مقترح لتطوير الذات لدى مديري المدارس العربية داخل الخط الأخضر؟ الأنة

أهداف الاراسة

هدفت الدراسة إلى التعرف على البرنامج التدريبي مقترح لتطوير الذات لدى مديري المدارس العربية داخل الخط الأخضر.

أهمية الاراسة

تتمثل أهمية الدراسة الحالية من خلال ما ستقدمه من معلومات عن البرامج التدريبية لتطوير الذات للمديرين و المعلمين

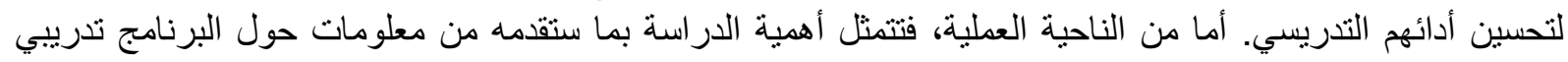

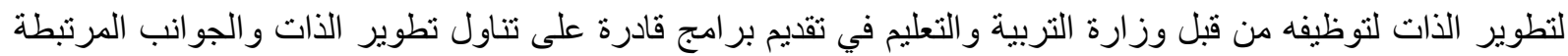

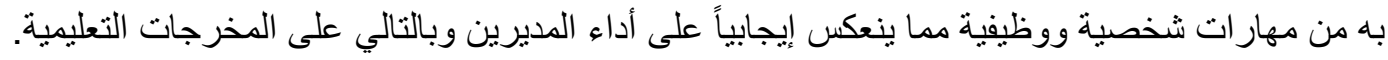

$$
\text { التعريفات الإجرائية }
$$

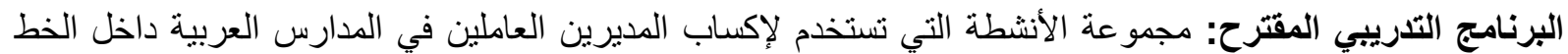

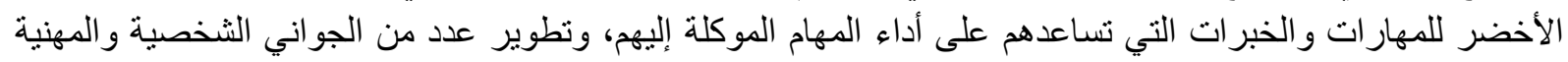
التي تساعدهم على أداء دور هم بكفاءة. 
تطوير الذات: مجموعة الأنشطة المقترحة في البرنامج التدريبي بهدف تنمية عدد من الخصائص الثخصية والمهنية

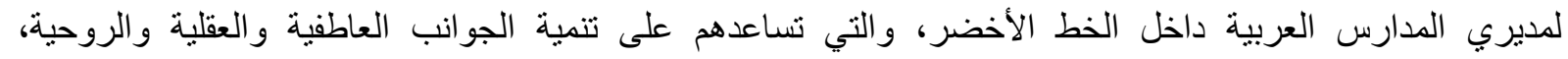
و الاجنماعية، و الصحية، و الإبداعية.

الطريقة والإجراءات

منهج الاراسة

لتحقيق هدف الدراسة، تم استخدام المنهجية النوعية المستندة إلى تحليل المحتوى باعتباره من الأساليب المستخدمة لدر اسة

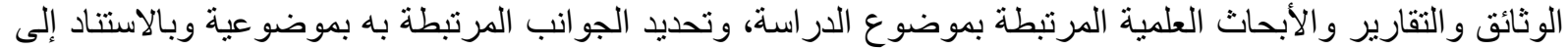

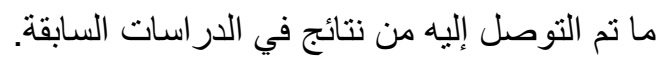

نتائج الاراسة

للإجابة عن سؤال الدراسة، تم اقتراح البرنامج التدريبي المقترح لتطوير الذات لمديري المدارس العربية داخل الخط

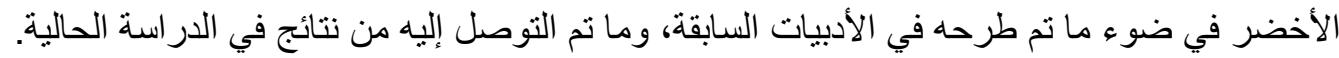

أولا: تعريف البرنامج التدريبي المقترح لتطوير الذات لمديري المدارس العربية داخل الخط الأخضر يمكن أن يعرف البرنامج التدريبي المقترح لتطوير الذات لمديري المدارس العربية داخل الخط الأخضر بأنه مجموعة

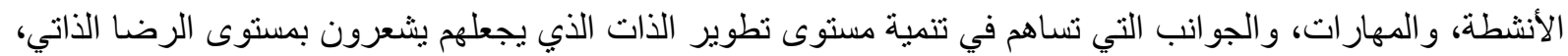

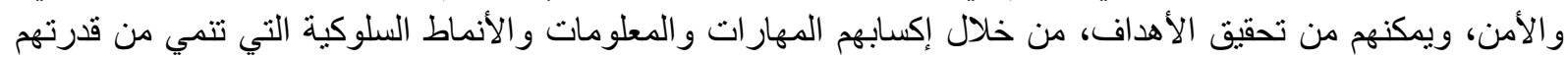

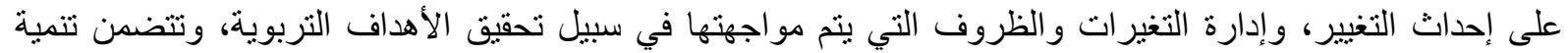

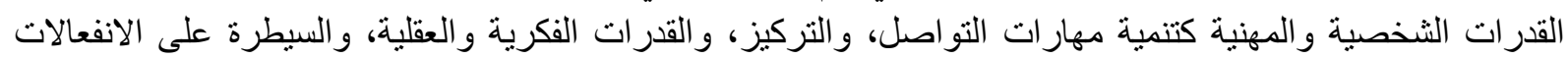

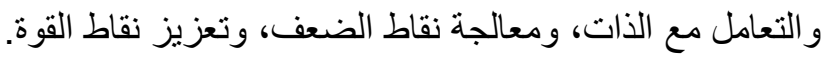

ثانياً: فلسفة البرنامج التدريبي المقترح

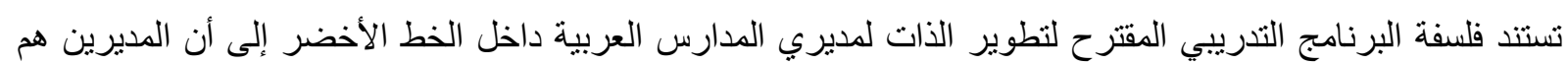

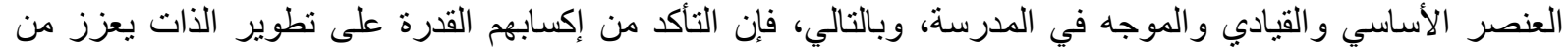

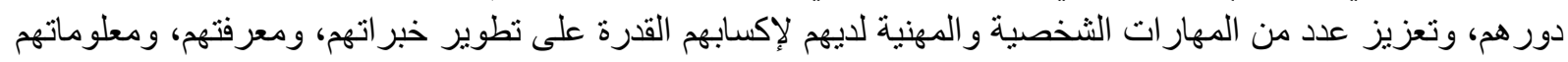
، وتنمية الجو انب العاطفية، و العقلية، و الروحية، و الصحية، والإبداعية لديهر.

ثالثاً: أهداف البرنامج التدريبي المقترح

يهدف البرنامج التدريبي المقترح لنطوير الذات لمديري المدارس العربية داخل الخط الأخضر إلى تحديد ما يلزم من خطط، و أدوات تساهم في تطوير المناهج العربية، كما يلي:

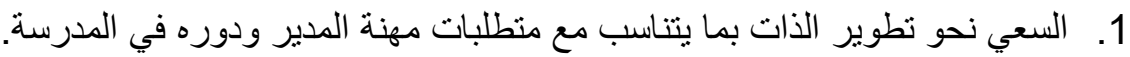
2.

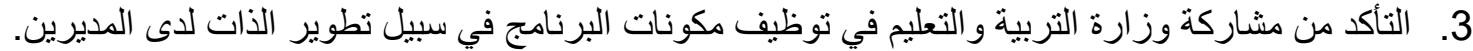

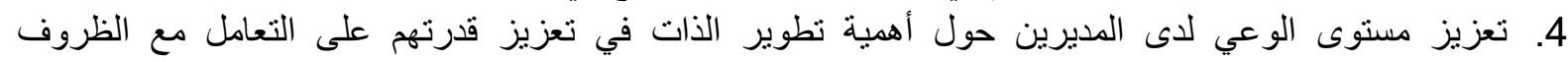

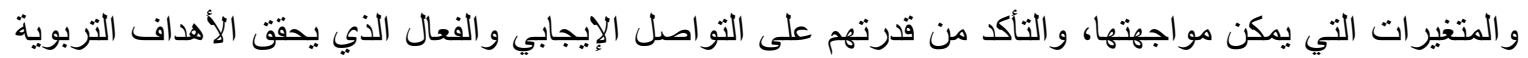

و التعليمية.

رابعاً: المبادئ الأساسية للبرنامج التدريبي المقترح

يقوم البرنامج التدريبي المقترح على مجمو عة من المبادئ الأساسية، وهي:

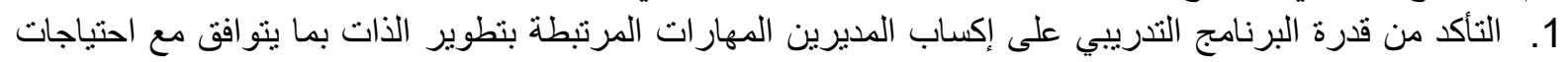

المديرين واحتياجات العملية التربوية و التعليمية. 
2. التركيز على الجوانب المرتبطة بتطوير الذات لتحقيق التكامل لنخصية المديرين وقدرتهم على التكيف مع الظروف

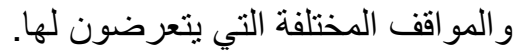

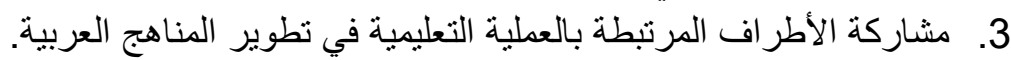
4. التأكد من قدرة المديرين على تطوير ذاتهم بصورة مستمرة لضمان مستوى من الكفاءة والفاعلية والجودة في الأداء 5. التأكد من نوظيف التيكي. و التعليمية. 6. ربط البرنامج المقترح بالخطط الاستراتيجية و التعليمية المرتبطة بتطوير الأداء في وزارة التربية والتعليم، والتأكد

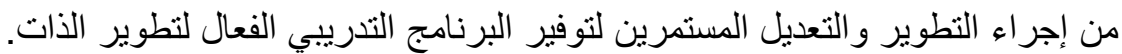

خامساً: جوانب البرنامج التدريبي المقترح يتضمن البرنامج التدريبي المقترح التركيز على عدد من الجوانب المرتبطة بتطوير الذات، وهي كالآتي: ـ الجاتب الروحي: يركز البرنامج التدريبي المقترح على تعزيز القيم الأخلاقية والجوانب الإنسانية، والصفات الإيجابية

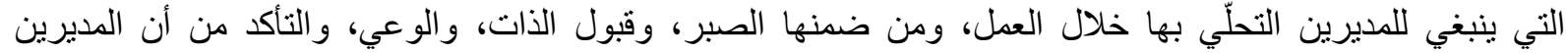

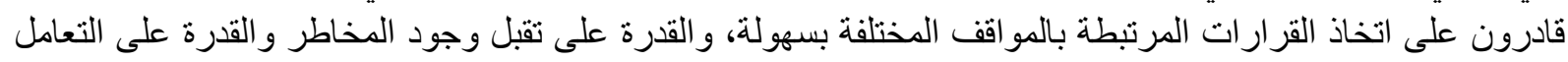

ـ الجاتب العاطفي: يركز البرنامج التدريبي على تعزيز الجوانب المرتبطة ببناء العلاقات و التفاعل الاجتماعي، بحيث يتم

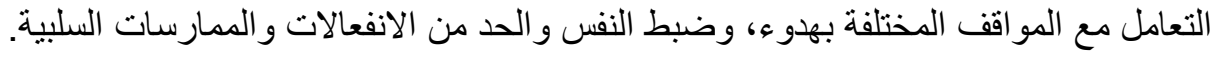

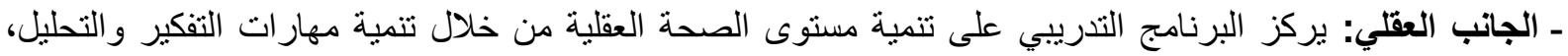

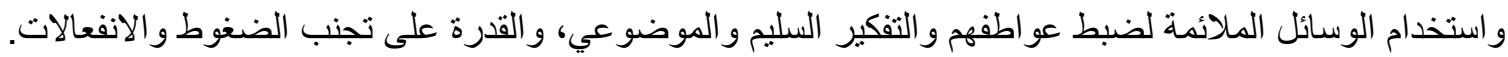

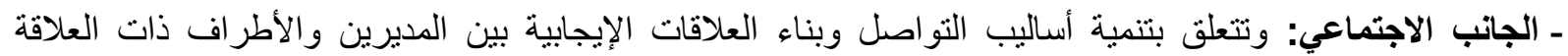

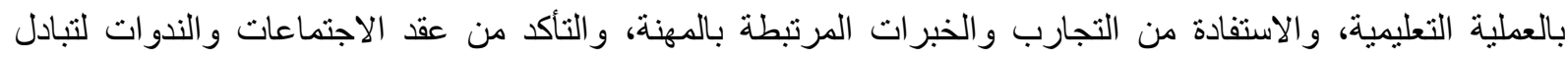
المعلومات بين المؤسسات التعليمية وبناء العلاقات بينهم.

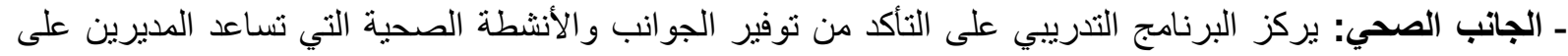
أداء المهام بكفاءة، من خلال التأكيد على أهمية عدد من العادات الصحية والأنشطة البدنية على مستوى النشاط و الصحة

لايههم.

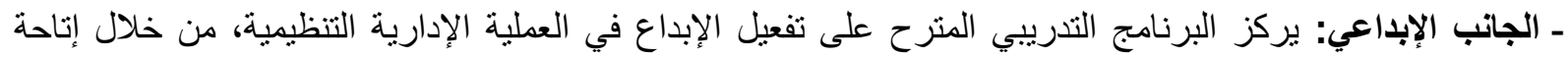

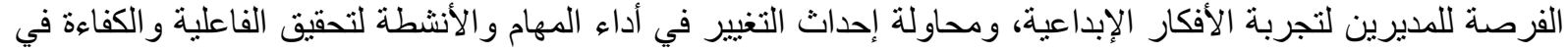

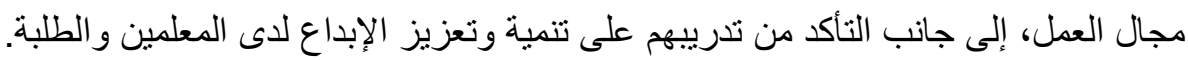

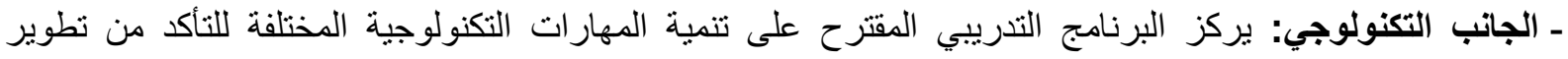

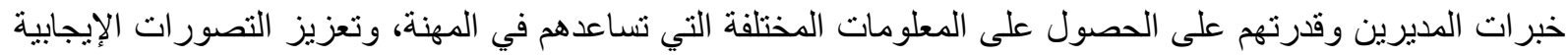
حول استخدامها في الأنشطة المختلفة المرتبطة بالمدرسة. سادساً: مهارات تظوير الذات ضمن البرنامج التدريبي المقترح يتضمن البرنامج التدريبي المقترح التركيز على تطوير عدد من المهار ات لدى المديرين، وهي:

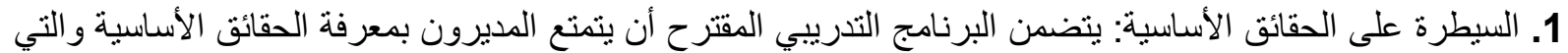

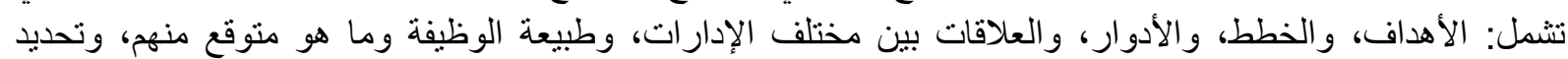
الطرق التي يتم من خلالها الحصول على المعلومات وات عند العاجة العاتة إليها.

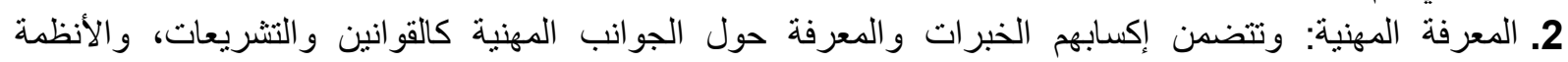
و اللوائح، وتكنولوجيا التعليم، و أسس الجودة، ومصادر التمويل، و التخطيط، و التنظيم، و التوجيه، و الرقابة. 3. الحساسية للحدث: يعدّ التأكد من قدرة المديرين على الثعور بالمشكلة من الجوانب التي تساهم في القدرة على تحديدها

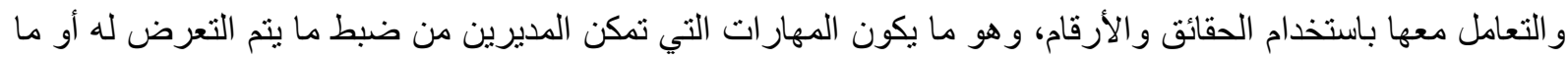

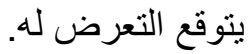


4. مهار ات التحليل و اتخاذ القرار: يتضمن البرنامج التدريبي المقترح التأكد من نطوير مهارات اتخاذ القرار من خلال

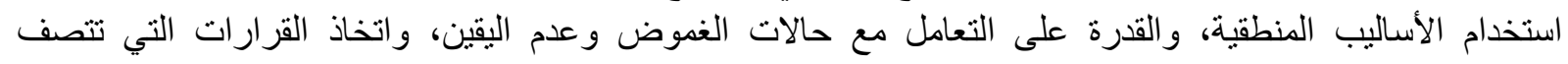

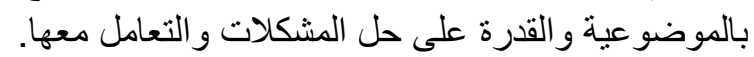

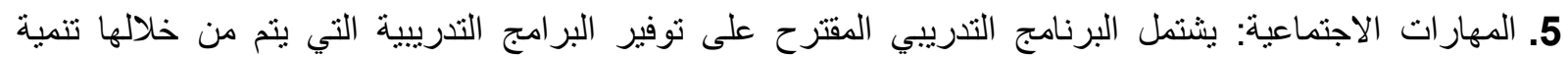

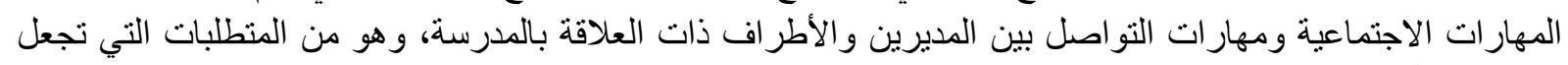

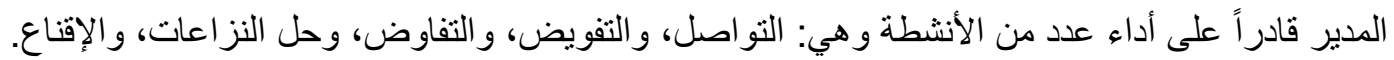

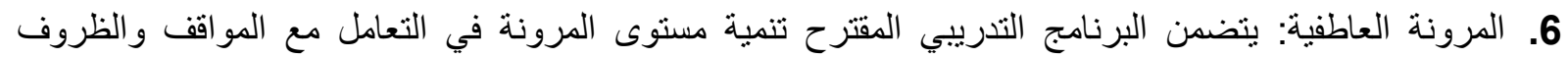

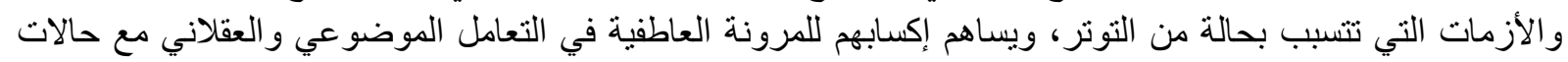

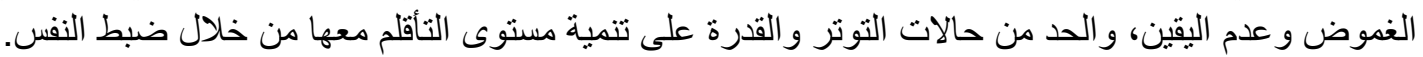

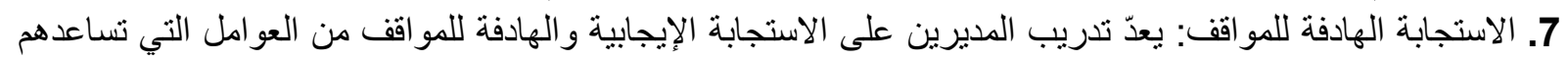

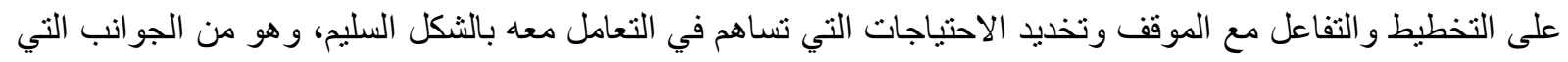

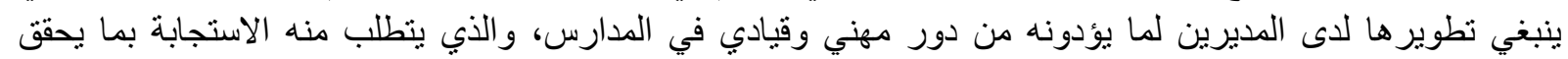
الأهداف التعليمية و التربوية. 8. الإبداع: بساهم تدريب المديرين على تطبيق الأفكار الإبداعية في التعامل مع الظروف والمشكلات، وتنمية الأداء

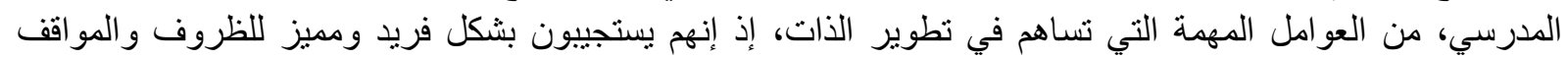

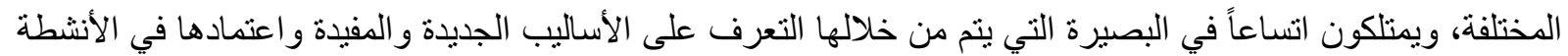
المؤسسبة المختلفة. 9. خفة الحركة الذهنية: يعدّ تدريب المديرين على خفة الحركة الذهنية من الجوانب المعززة لقدرتهم على أداء دورهم

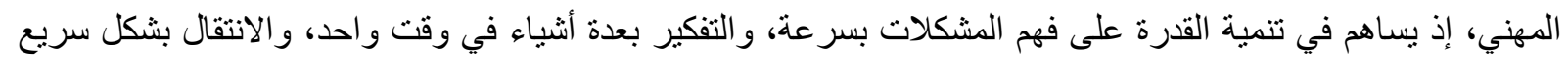

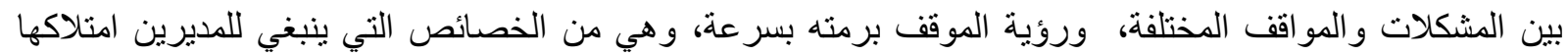

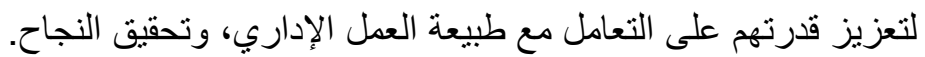

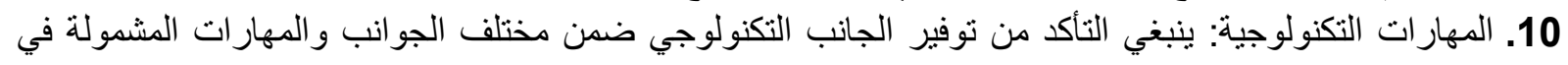

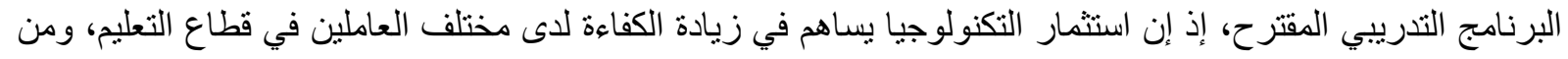

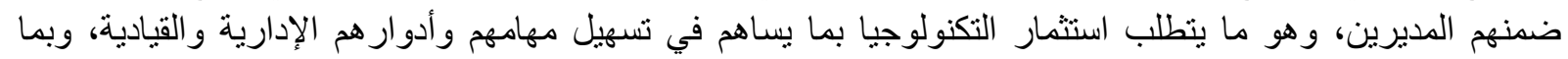

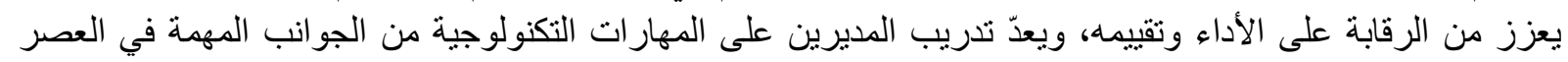

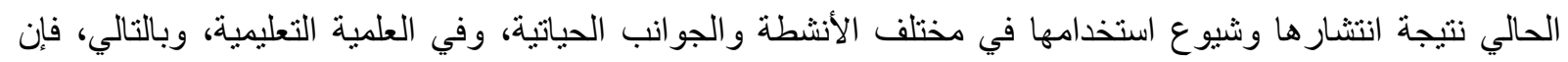
إكسابهم التدريب الكافي حولها يزيد من مستوى الوعي و الإدر الك للجوانب الإيجابية لتطبيقها.

\section{سابعاً: مكونات البرنامج التدريبي المقترح}

يشمل البرنامج التدريبي المقترح لتطوير الذات لدى مديري المدارس العربية على عدد من المكونات، وهي:

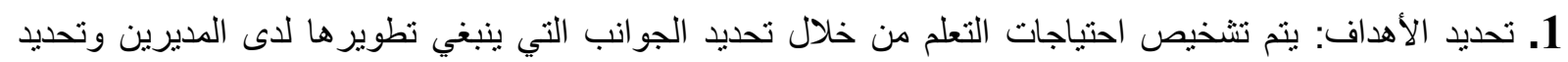

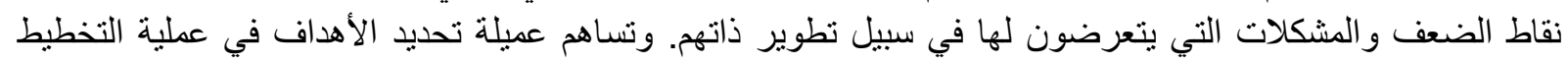

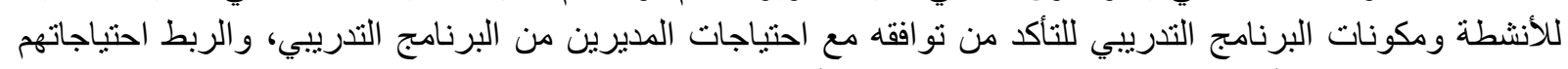
ومنطلبات المهنة، و التأكد من تضمين التكنولوجيا لتونيا ضمن الأهداف التعليمية.

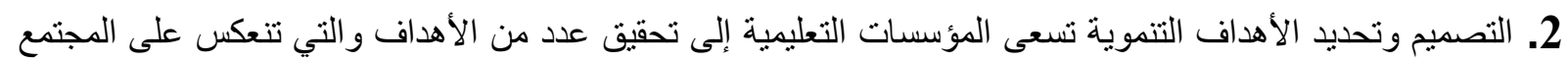

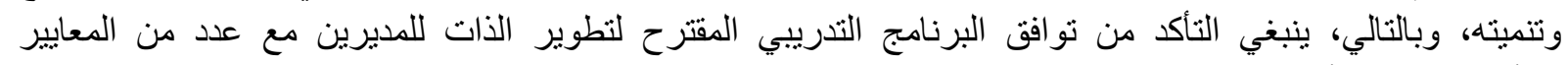

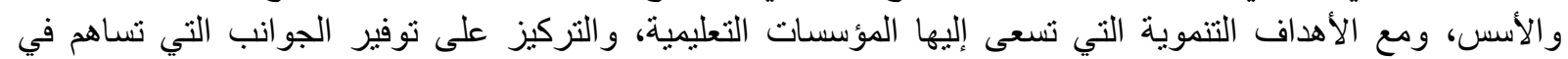

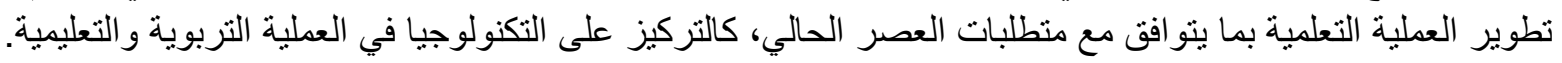

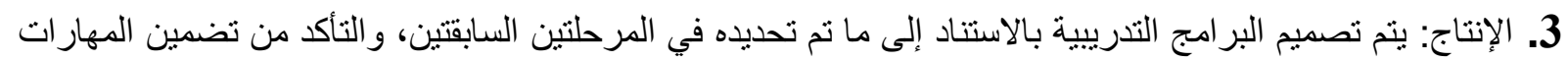

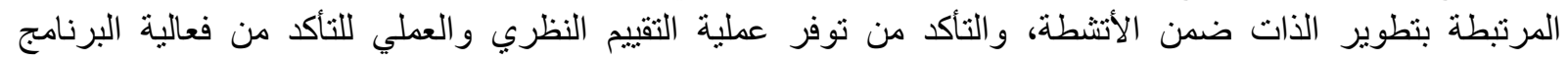
التدرييس في تنمية المهار ات المرتبطة بتطوير الذات لدى المديرين، وينبغي أن تتميز تلك الأنشطة بالو اقعية و المنطقية، وبتو افقها مع متطلبات العصر الحالي.

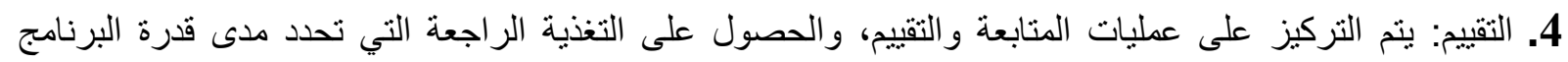

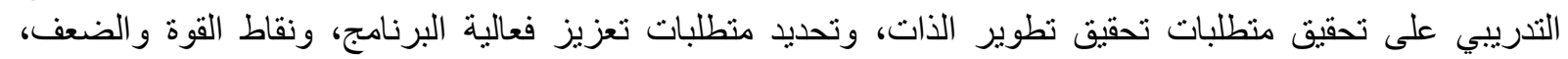


وتساهم عملية التقييم في تحديد مدى فاعلية البرنامج التدريبي على تطوير الذات لمديري المدارس العربية، وتحديد نقاط

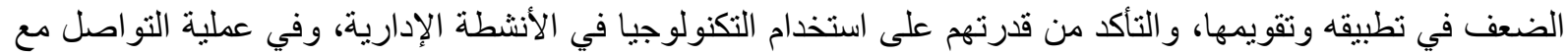

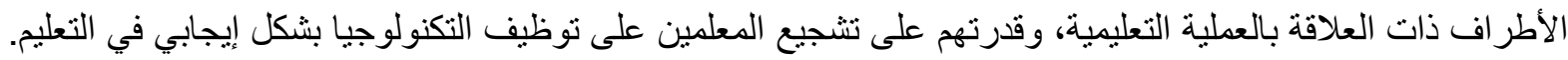

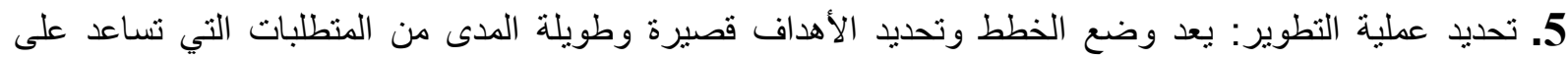

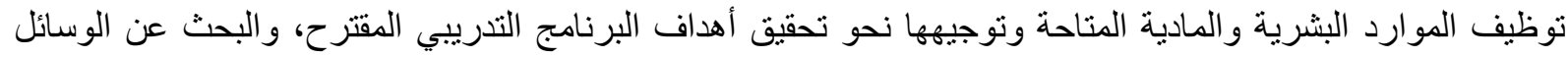

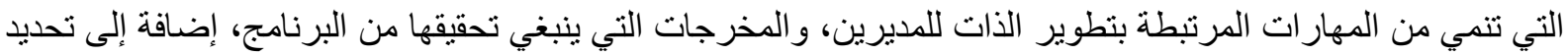

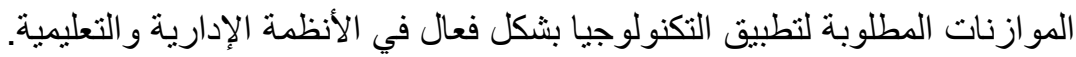

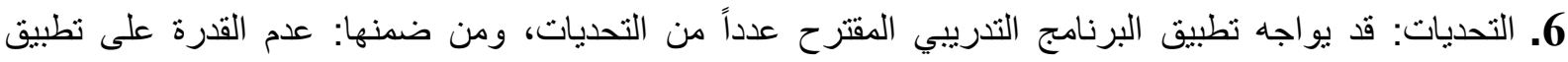

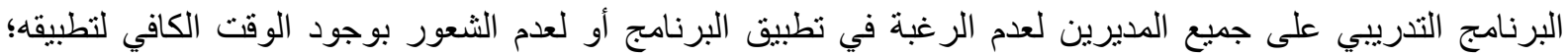

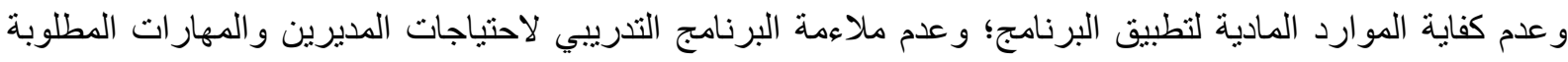

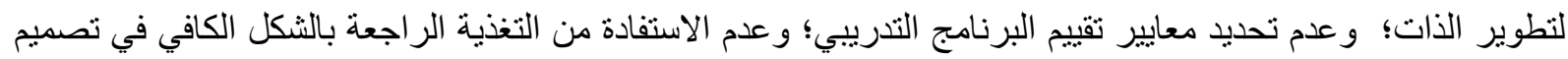

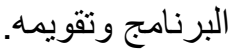

مناقشة النتائج

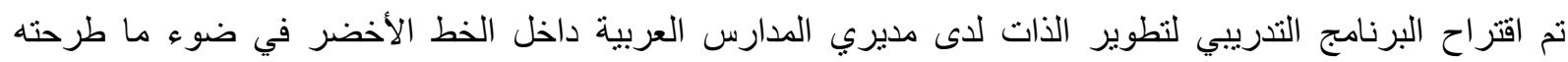

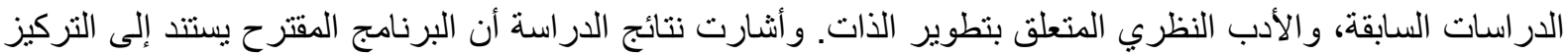

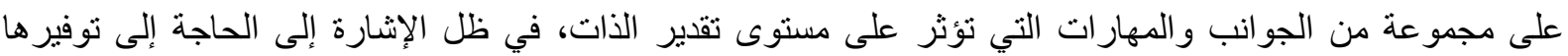

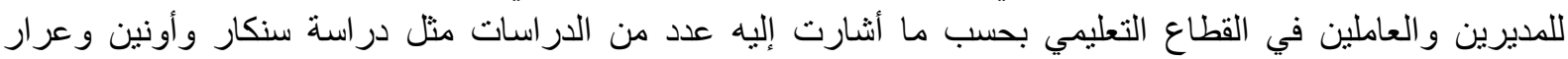

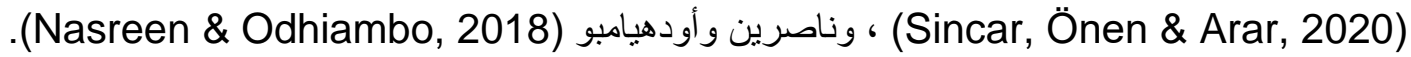

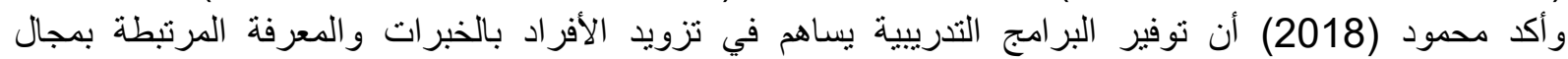

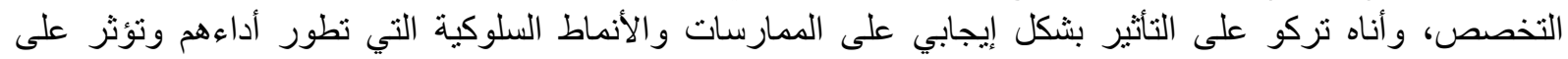

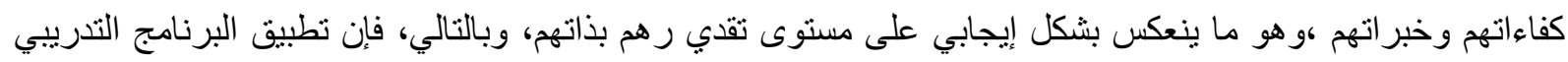

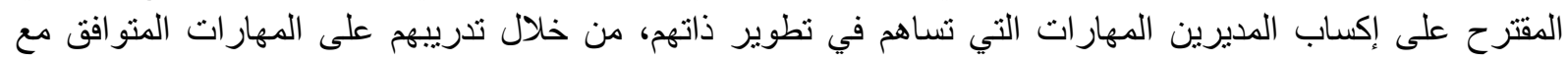

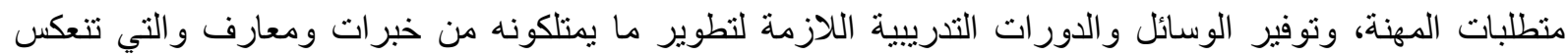

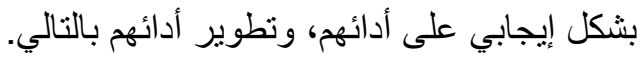
و أكد أوغور وكوش (Uğur \& Koç, 2019) أن تدريب الأفراد العاملين في قطاع التعليم على استخدام التكنولوجيا

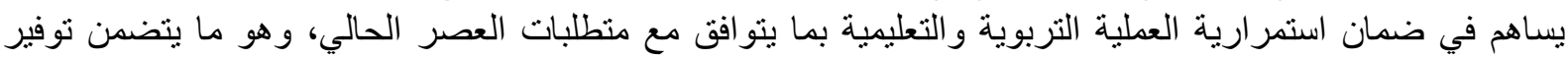

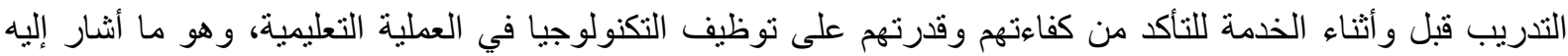

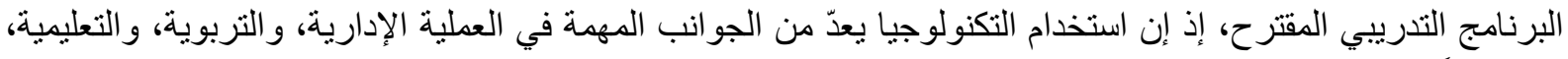

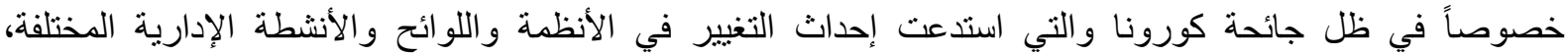

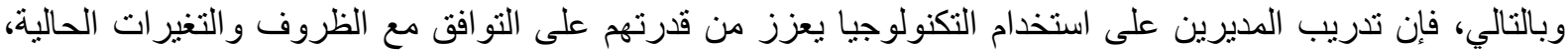

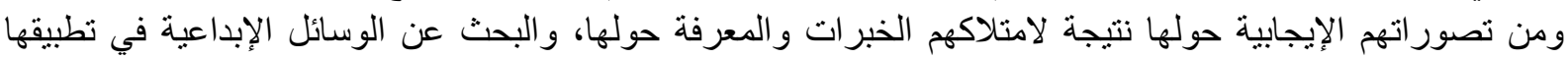

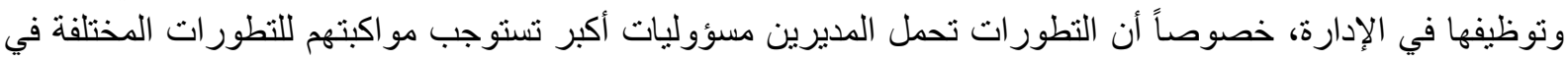

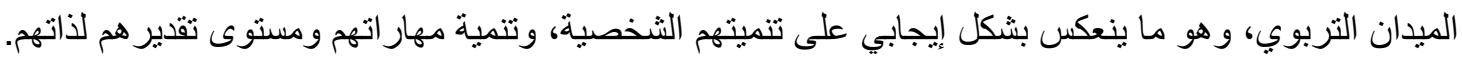

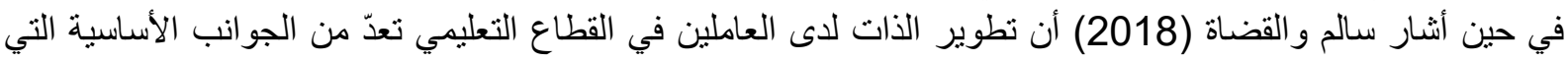

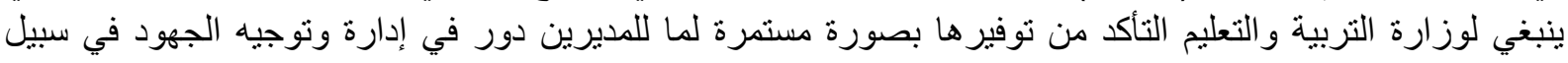

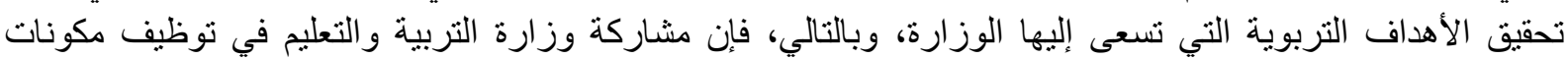

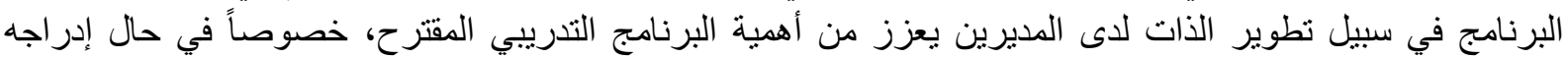

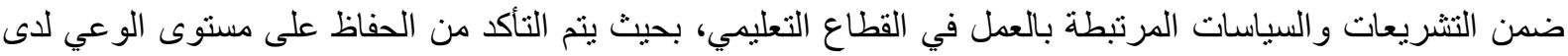

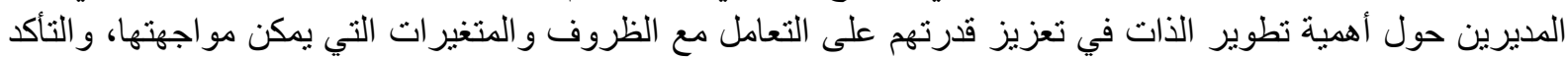
من قدرنهم على التو اصل الإيجابي و الفعال الذي يحقق الأهداف التربوية والتهائ التعليمية.

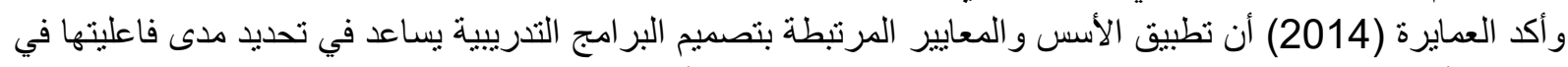
تحقيق الأهداف المرجوة منها، وبالتالي، فإن التركيز على تطبيق الأسس والمعايير المرتبطة بتصميم البرنامج التدريبي، 


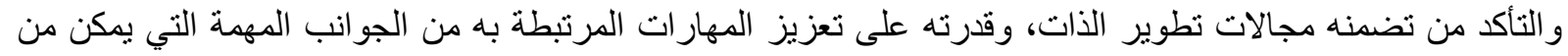

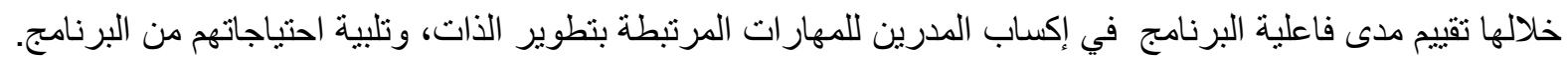

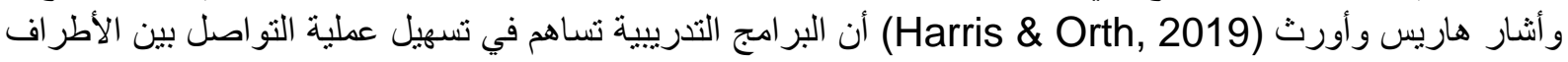
ذات العلاقة بالعملية التعليمية، والذي يوفر التخذية الراجعة والمعلومات الدقيقة حول الأداء و الأنشطة المختلفة داخل البيئة

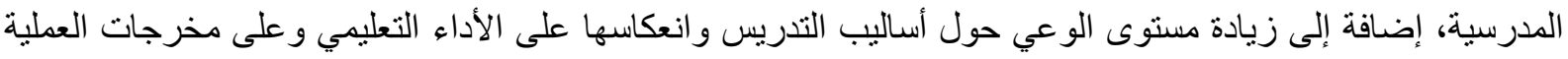

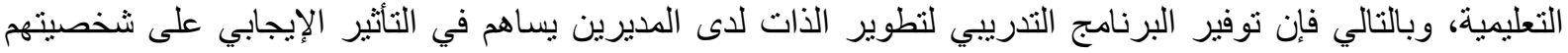

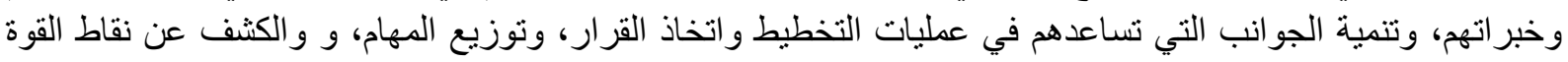

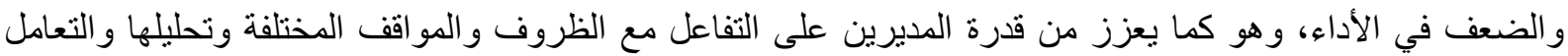

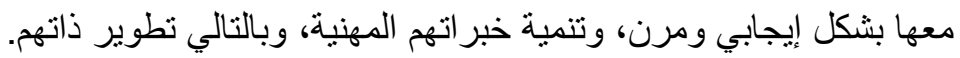

التوصيات

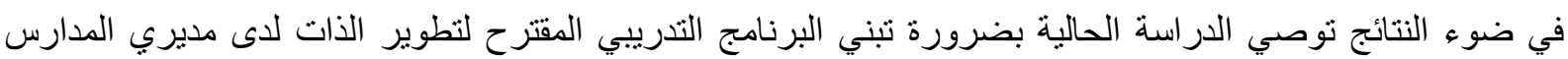

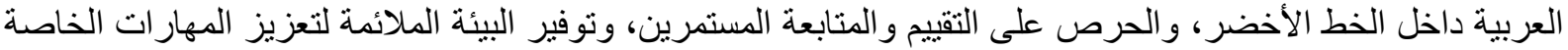

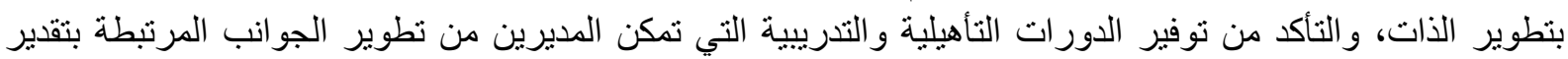
الذات لديهم.

\section{المراجع العربية}

سالم، حسني و القضاة، محمد أمين. (2018). أنموذج تربوي مقترح لتحسين عمليات تبادل المعرفة بين وزارة التربية

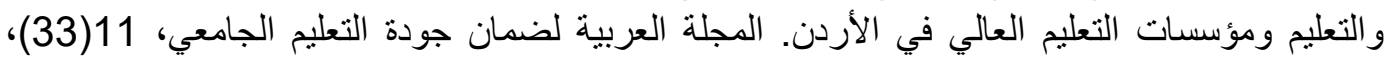

.173-147

العبد الكريم، راثند والملا، أحلام. (2014). فاعلية برنامج تدريبي لتطوير مشاركة مديرات مدارس المرحلة الابتدائية

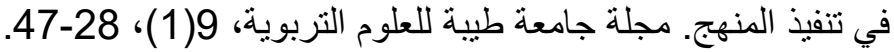

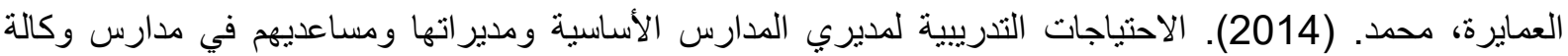

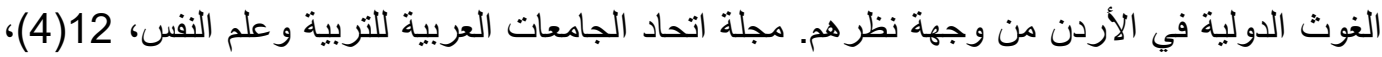

محمود، خالد. (2018). بناء برنامج تدريبي مقترح لتنمية الكفايات التعليمية الأدائية لمعلمات التعليم قبل المدرسة أثناء الخدمة بو لاية الجزيرة-السودان. المجلة الدولية للار اسات التربوية و النفسية، 3(3)، 704-719.

المراجع الإنجليزية

Divyapriyadharshini, N. \& Devika, U. (2020). Leadership development program for first time managers -design and its importance. International Journal of Research \& Innovation in Social Science (IJRISS), 5(4), 333-336.

Harris, M., \& Orth, U. (2019). The link between self-esteem and social relationships: a meta-analysis of longitudinal studies. Journal of Personality and Social Psychology, Doi: 10.1037/pspp0000265, 1-19.

Hayward, R. \& Krause, N. (2014). "Religion, mental health, and wellbeing: social aspects" in Religion, personality, and social behavior. New York: Psychology Press.

Ivaniuk, H., Venhlovska, O., Antypin, Y., \& Vovchok, Y. (2020). Self-development as a factor in the professional growth of Future Teachers. Journal of History Culture and Art Research, 9(4), 77-86 
Karwowski, M. (2015). Development of the creative self-concept. Creativity Theories - Research - Applications 2(2), 165-179.

Megheirkouni, M. (2016). Factors influencing leadership development in an uncertain environment .Journal of management development, 35(10), $1232-1254$.

Nasreen, A. \& Odhiambo, G. (2018). The continuous professional development of school principals: current practices in Pakistan. Bulletin of Education and Research, 40(1), 245-266.

Osborne, S. \& Hammoud, M. (2017) . Effective employee engagement in the workplace. International Journal of Applied Management and Technology, 16(1), 50-67.

Shirbagi, N. (2018). An assessment of skill needs of a sample of Iranian school principals based on "successful leaders' self-development model". Pedagogy Studies / Pedagogika, 130(2), 76-91.

Sincar, M., Önen, Z. \& Arar, K. (2020) . An investigation of Turkish female school administrators' views on the concept of self-development. International Journal of Leadership in Education, 23(2), 175-198.

Spry, N. \& Marchant, T. (2014). How a personal development program enhances social connection and mobilises women in the community. Australian Journal of Adult Learning, 54(2), 33-53.

Stancui, S. (2019) . Self-development of future university professors: stimulating the formation of young students. Social Work Review / Revista de Asistenta Sociala, 18(1), 25-34.

Uğur, N. \& Koç, T. (2019). Leading and teaching with technology: school principals' perspective. International Journal of Educational Leadership \& Management, 7(1), 42-71.

VanderWeele, T. (2017). Religious communities and human flourishing. Curr. Dir. Psychol. Sci., 26: 476-481.

Villani, D., Sorgente, A. \& lannello, P. (2019) . The role of spirituality and religiosity in subjective well-being of individuals with different religious status. Front. Psychol., 10: 1-11.

Worthington, E., Hook, J., Davis, D. \& McDaniel, M. (2011). Religion and spirituality. J. Clin. Psychol., 67: 204-214.

Zawadzka, A. \& Szabowska-Walaszczyk, A. (2014). Does self-improvement explain well-being in life and at workplace? Analysis based on selected measures of well-being. Polish Psychological Bulletin 45(2), 128-141. 